\title{
The Relative Informativeness of Regular and E-Mini Euro/Dollar Futures Contracts and the Role of Trader Types
}

\author{
Jatin Malhotra ${ }^{1}(\mathbb{D})$ and Angelo Corelli ${ }^{2, *}$ (C) \\ 1 Center of Excellence for Research in Finance and Accounting (CERFA), American University in Dubai, \\ Dubai P.O. Box 28282, United Arab Emirates; jatin.82@gmail.com \\ 2 Maastricht School of Management, Endepolsdomein 150, 6229 EP Maastricht, The Netherlands \\ * Correspondence: corelli@msm.nl; Tel.: +31-4338-70887
}

check for updates

Citation: Malhotra, Jatin, and Angelo Corelli. 2021. The Relative Informativeness of Regular and E-Mini Euro/Dollar Futures Contracts and the Role of Trader Types. Risks 9: 111. https://doi.org/ 10.3390/risks9060111

Academic Editor: Mogens Steffensen

Received: 20 March 2021

Accepted: 2 June 2021

Published: 6 June 2021

Publisher's Note: MDPI stays neutral with regard to jurisdictional claims in published maps and institutional affiliations.

Copyright: (c) 2021 by the authors. Licensee MDPI, Basel, Switzerland. This article is an open access article distributed under the terms and conditions of the Creative Commons Attribution (CC BY) license (https:// creativecommons.org/licenses/by/ $4.0 /)$.

\begin{abstract}
This paper examines the relative contribution of regular and e-mini futures market to price discovery of EUR/USD futures contracts on the Chicago Mercantile Exchange (CME), using intraday data in 2010.The relative contribution to price discovery is estimated using the information share approach proposed by Hasbrouck and Gonzalo-Granger. Empirical findings indicate that regular futures market contributes significantly to the price discovery, accounting for approximately $66.5 \%$ of price discovery in the EURO/USD market. This study also examines if the regular future's information share (IS) can be explained by the positioning of commercial and non-commercial traders. We find a positive significant relationship between IS and both the speculative trade position and hedgers trade position. The results support the conclusion that the IS of regular futures can be better explained by speculators than hedgers.
\end{abstract}

Keywords: e-mini-futures; intraday; price discovery; information share; speculators; hedgers

\section{Introduction}

The paper analyzes how regular and e-mini futures market contributes to the price discovery of the EUR/USD futures contracts on the Chicago Mercantile Exchange (CME). The dataset includes intraday data, which have been proven to be very useful in the process, as recently demonstrated by Martinez and Tse (2018), Fassas and Siriopoulos (2019), and Inani (2017). Since small traders are more likely to trade e-mini futures, the aim is to find out the relative contributions of large and small traders to price discovery and how they react to new information using the information share (IS) approach proposed by Hasbrouck (1995), Gonzalo and Granger (1995). ${ }^{1}$

The equilibrium price in financial markets is determined by a process of price discovery, based on incorporation of new information, as demonstrated by Narayana et al. (2016). The process is particularly important in the market of currency futures, given the large market size, and high volumes traded, as shown by Chen and Tsai (2017) among others.

Currency market is among the largest and fastest growing markets in the world, with average daily turnover of $\$ 4$ trillion in 2010, which is $20 \%$ higher than 2009 numbers. Out of this, 37\% represents an increase in the currency futures market. ${ }^{2}$ Within this market, EUR/USD is by far the dominant pair, with a $28 \%$ share in the global currency futures market turnover by currency pair. ${ }^{3}$

This absolute dominance over other currency pairs begs for a more detailed analysis. The market of the Euro currency futures in Chicago Mercantile Exchange (CME) ranks first out of twenty foreign exchange futures traded ranked by the number of contracts. ${ }^{4}$ A total of 85,370,148 contracts were traded in 2010, up from 53,873,989 contracts in the previous year, with an increase of $58.46 \%$. Similarly, the number of contracts traded in e-mini EUR/USD futures market increased from 657,689 contracts to 1,237,773 contracts, which is an $88.20 \%$ jump. ${ }^{5}$ This is by far the highest percent volume increase on CME and makes it one of the most tradable markets in recent years. Hence, we hypothesize 
that as compared to the e-mini futures market, the regular futures market contributes significantly to the price discovery in the EUR/USD market. This is consistent with the results from Crain and Lee (1995), Martens and Kofman (1998), Chatrath and Song (1998) and Rosemberg and Traub (2007).

This paper also examines if trader type in the CME regular futures market can explain information share (IS). The aim is to understand how different types of traders have relative importance compared to the IS and their leadership in generating information. The structure of the dataset, with trader types classified as commercial vs. non-commercial by the Commodity Futures Trading Commission (CFTC) allows the study of the effects of proprietary trading by various types of traders. ${ }^{6}$ Categorizing theses traders is important to understand the role they play in financial markets.

The interpretation of this relationship between the IS and trader type classification can be used to determine which of the trader type (commercial and non-commercial) reflects higher degree of private information. Representative studies by Scholes (1972) and Evans and Lyons (2002) conclude that there is a positive correlation between order flow and exchange rate movements. They interpret this as the traders placing the orders having private information. ${ }^{7}$

We hypothesize that the IS of regular futures can be better explained by speculators than hedgers. We expect to find large traders in the regular futures market have access to better information than the small trades in the e-mini futures market. The combination of better skills and more information is the key to the differences in the ability to find and exploit good investment opportunities. These large investors are more likely to be institutional investors with greater financial, technical and analytical skills and hence more informed. A large body of literature indicates that the regular futures markets have fewer constraints, higher advantage, lower transaction costs, and instruments that make it easy to speculate and hedge which makes it an ideal market for informed investors.

Studies by Ates and Wang (2005), Tse and Xiang (2005), Tse et al. (2006), Tao and Song (2010) Lakonishok and Maberly (1990), Nofsinger and Sias (1999), Barber and Odean (2000), Chakravarty (2001), and Malmendier and Shanthikumar (2007) all analyze trader types and suggest that small traders are mostly individual traders in the e-mini futures markets that usually have limited capital and are relatively less informed than the large traders as they lack the technical and analytical skills to make sound financial decisions. They find that index futures market dominates e-mini market in price discovery.

The contribution of the paper to the existing literature is twofold. Firstly, this is the first attempt to examine the relative contribution of the regular vs. e-mini futures markets to price discovery of EUR/USD futures contracts. Li et al. (2020) examine price discovery process of EUR/USD futures trade in Chicago Mercantile Exchange (CME) and Intercontinental Exchange (ICE). This is also the first paper that compares regular and e-mini contracts in the currency futures market Studies by Kurov and Lasser (2004), Ates and Wang (2005), Tse et al. (2006) and Tao and Song (2010) analyze price discovery between regular and e-mini index futures market, but no study has compared regular and e-mini contracts in currency futures market.

Secondly, this is the first paper that analyzes the contribution of trader type to information share (IS) in the currency markets. This allows for an examination of the proportionate share of price discovery in the futures market between commercial (hedger) andnoncommercial (speculator) traders. Studies by Klitgaard and Weir (2004) and Gorton et al. (2012) show that either private information or trend chasing behavior is present among speculators. More recently, they also developed good skills in technical and fundamental analysis, although this comes at a cost (Hoffmann and Shefrin 2014). However, they do not analyze the information shared. Related study by Schwarz (2011) analyzes the relationship between positioning of hedgers and speculators and returns in equity future markets. The analysis shows evidence to support private information hypothesis; revelations of speculative positions are informative to investors. By analyzing the relationship between hedgers, 
speculators and information share, we attempt to determine the relative contributions of different traders to price discovery in financial markets.

The rest of the study is organized as follows. Section 2 describes the related literature followed by Section 3 that describes data and Section 4 provides the methodologies and results. Section 5 offers concluding remarks.

\section{Literature Review}

\subsection{Price Discovery}

Studies on currency futures by Crain and Lee (1995), Martens and Kofman (1998), Chatrath and Song (1998) and Rosemberg and Traub (2007) examine the price leadership between regular futures and foreign exchange (FX) spot market and conclude that the foreign exchange futures market plays a leading role in price discovery. ${ }^{8}$ This is due to a high level of transparency in the futures markets in comparison to the spot market as suggested by Hasbrouck (2004). On the other hand, Poskitt (2009) and Chen and Gau (2010) find that regular futures have lower information share than spot. ${ }^{9}$ Greppmair and Theissen (2019) find that the introduction of e-mini contracts is beneficial as they increase liquidity and reduces volatility in the regular contracts. Among studies that compare three markets simultaneously in currency futures market, Tse et al. (2006) concluded that relative contribution to price discovery in GLOBEX electronic futures dominates floor futures and spot trading in the EUR/USD FX market and spot trading dominates futures trading in the YEN/USD market. Floor trading futures markets contribute the least to the price discovery for both currencies, consistent with Theissen (2002) and Hasbrouck (2003) study on stock markets. However, Cabrera et al. (2009) conclude that EBS electronic interdealer spot dominates GLOBEX futures and e-mini futures in price discovery for both EUR/USD and YEN/USD exchange markets. They conclude that the leadership in spot market is due to the large size of the interdealer spot market (EBS). Cabrera et al. (2009) also suggest that Tse et al. (2006) find different results for the EUR/USD exchange rate because the spot platform that they use (CMC) is likely to have uninformed traders. Fassas and Siriopoulos (2019) finds that the micro e-mini futures contract performance very well to the price discovery in the Greek market. Martinez and Tse (2018) find that spot foreign exchange market in Mexico leads the future foreign exchange market in price discovery. However, Inani (2017) finds that the futures market is more efficient than the spot market in India.

\subsection{Market Microstructure}

Microstructure theories usually assume that informed traders are usually insiders who have private information about the firms. However, knowledge of specific security may not be an important source of information in the futures markets because according to Subrahmanyam (1991) such information is diversified. However, this does not lead to efficient market as some traders are more efficient in interpreting publicly available information or can react faster to the new information than other traders. Lyons (1995), Yao (1998) and Payne (2003) all use data from foreign exchange dealers and conclude that spreads contain information component. Hence, price discovery takes place either because some traders are more efficient in interpreting publicly available information or because they react faster to the new information than other traders

Webb and Smith (1994), Wang et al. (1994) and Ates and Wang (2005) all conclude that liquidity is one of the components that determine the rate of price discovery in the foreign exchange futures markets. This implies that traders generating liquidity in the futures markets lead to price discovery. Klitgaard and Weir (2004) and Gorton et al. (2012) examine publicly available data on the weekly commitments of trader's reports published by U.S. Commodity Futures Trading Commission (CFTC) and find a strong relationship between changes in speculators net positions and changes in exchange rates. They interpret this as evidence of either private information or trend chasing behavior of speculators. Gorton et al. (2012) also ran a regression of returns on speculative levels for nonfinancial firms and interpreted the results as evidence of trend chasing behavior. 


\section{Methodology}

\subsection{Information Share Approach}

Following the approach of Hasbrouck (1995), this paper estimates the information share (IS) ${ }^{10}$ measure based on the vector error correction model (VECM) developed by Engle and Granger (1987). Time series of mid-quotes for EURO/USD futures and e-mini traded on CME are generated over the sample period in 2010. We extract the most actively traded nearest-to-maturity contract for each month. Five days prior to its expiration the next-maturity contract is selected in the sample. The quotes must be two-sided, with a positive value of bid-ask spread.

We form time series of the futures'mid-quotes from 17:00 CST to 16:00 CST next day during the period of January 2010 to December 2010. Midquote returns are calculated fromthetimeseriesoftheprevailingfuturesmid-quotesampledatone-second and weekly sampling interval. The unit root test for stationarity of mid-quote series is performed. We use Johansen (1988) method to check whether the regular and e-mini futures on CME are co-integrated. The vector error correction model (VECM) is defined as:

$$
\begin{gathered}
\Delta P_{\text {reg }, t}=\alpha_{\text {reg }, o}+\gamma_{\text {reg }}\left(P_{\text {reg }, t-1}+\beta_{\text {emini }} P_{\text {emini }, t-1}\right)+\sum_{q=1}^{Q} \delta_{q} \Delta P_{\text {reg }, t-q}+\sum_{q=1}^{Q} \eta_{q} \Delta P_{\text {emini }, t-q}+\varepsilon_{\text {reg }, t} \\
\Delta P_{\text {emini }, t}=\alpha_{\text {emini }, o}+\gamma_{\text {emini }}\left(P_{\text {reg }, t-1}+\beta_{\text {emini }} P_{\text {emini }, t-1}\right)+\sum_{q=1}^{Q} \delta_{q} \Delta P_{\text {emini }, t-q}+\sum_{q=1}^{Q} \eta_{q} \Delta P_{r e g, t-q}+\varepsilon_{\text {emini }, t}
\end{gathered}
$$

where

$\Delta P_{\text {reg,t }}$ are the first log difference of the futures mid-quotes for regular futures.

$\Delta P_{\text {emini, }}$ are the first log difference of the futures mid-quotes for e-mini futures.

$\beta_{\mathrm{emini}}$ is the co-integrated vector between the two markets such that $\beta_{\text {reg }} P_{\text {reg, },-1}+$ $\beta_{\text {emini }} P_{\text {emini, } t-1}$ is co-integrated of order 1 .

$Q$ is the number of lags in the model based on multivariate Schwarz Bayesian criterion (Schwarz 1978).

The coefficients of the error correction term $\gamma_{\text {reg }}$ and $\gamma_{\mathrm{emini}}$ (adjustment coefficients) indicate the responsiveness of the mid-quote series to any deviation from the equilibrium relationship. $\varepsilon_{r e g, t}$. In addition, $\varepsilon_{\mathrm{emini}, t}$ are the residuals that are not autocorrelated.

Hasbrouck (1995) defines the information share of one market as the proportion of the variance of price innovation attributed to the variance of the innovation in the market of interest. The contribution of one market to the price discovery process (i.e., share in price discovery) is defined as:

$$
I S=\frac{\gamma_{r e g}^{2} \sigma_{r e g}^{2}}{\gamma_{r e g}^{2} \sigma_{r e g}^{2}+\gamma_{\text {emini }}^{2} \sigma_{\text {emini }}^{2}}
$$

where the innovations are not correlated; $\sigma_{\text {reg }}^{2}$ and $\sigma_{\text {emini }}^{2}$ are estimated from the residual covariance matrix of the VECM and as:

$$
\begin{aligned}
& I S_{U B}=\frac{\left(\gamma_{\mathrm{emini}} \sigma_{\text {reg }}-\gamma_{\text {reg }} \frac{\sigma_{C I}}{\sigma_{\text {reg }}}\right)^{2}}{\gamma_{\text {reg }}^{2} \sigma_{\mathrm{emini}}^{2}-2 \gamma_{\text {reg }} \gamma_{\mathrm{emini}} \sigma_{C I}+\gamma_{\mathrm{emini}}^{2} \sigma_{\text {reg }}^{2}} \\
& I S_{L B}=\frac{\gamma_{\mathrm{emini}}^{2}\left(\sigma_{\text {reg }}^{2}-\frac{\sigma_{C I}^{2}}{\sigma_{\mathrm{emini}}^{2}}\right)^{2}}{\gamma_{\text {reg }}^{2} \sigma_{\mathrm{emini}}^{2}-2 \gamma_{\text {reg }} \gamma_{\mathrm{emini}} \sigma_{C I}+\gamma_{\mathrm{emini}}^{2} \sigma_{\text {reg }}^{2}}
\end{aligned}
$$

where

$\gamma_{\mathrm{emini}}$ is defined as the common factor component of e-mini futures.

$\gamma_{r e g}$ is defined as the common factor component of regular futures, respectively.

$\sigma_{r e g}$ is the standard deviation of regular futures.

$\sigma_{\text {emini }}^{2}$ is the variance of e-mini futures.

$\sigma_{C I}$ is the Cholesky factorization value. 
It is important to specify that the innovations are correlated and Subscripts UB and LB denote upper and lower bounds, respectively. According to Baillie et al. (2002), the mean of the upper and lower bounds is a reasonable estimate of a market's information share. A higher value of IS indicates a larger contribution from the regular contracts.

Data are analyzed for the presence of unit roots. We use the standard augmented Dickey-Fuller unit root test to confirm that we cannot reject the null hypothesis of a unit root for the regular and e-mini futures price series. The Johansen (1991) cointegration tests show that the regular and e-mini futures prices are cointegrated and hence share a common stochastic trend.

A regression model, similar to one used by Klitgaard and Weir (2004) and Schwarz (2011), is used to analyze how the positioning could affect contribution to price discovery.

$$
\ln \left(\frac{I S_{k}}{1-I S_{k}}\right)=c+\beta_{1} \ln (\text { NonCom })+\beta_{2} \ln (\text { Com })+\beta_{3} \ln (\text { NonRep })+\varepsilon
$$

where

$I S_{k}$ denotes the information share of the regular futures market calculated using the weekly sampling interval $k$ on every Tuesday.

$c$ is a constant.

$\ln (\mathrm{NonCom})$ is the logarithm of the open positioning data for non-commercial traders, $\ln (\mathrm{Com})$ is the logarithm of the open position for commercial traders. traders.

$\ln$ (NonRep) is the logarithm of the open positioning data for non-reportable (small)

The IS is constrained to the interval $[0,1]$. We use log transformation of IS = $\ln \left(\frac{I S_{k}}{1-I S_{k}}\right)$.

\subsection{Common Factor Component Weight Approach}

Let $p_{t}$ be a $(n \times 1)$ vector of $I(1)$ non-stationary, correlated with $h=n-1$ correlating factors, price series for the same underlying security in $n$ markets. The measure of $\operatorname{Var}(\mathrm{P})$ with cointegrating variables (error correction form) can be written following the Granger representation theorem, as in Cabrera et al. (2009).

$$
\Delta p_{t}=B z_{t-1}^{*}+s_{1} \Delta p_{t-1}+s_{2} \Delta p_{t-2}+\ldots+s_{p-1} \Delta p_{t-p+1}+\varepsilon_{t}
$$

Following Stock and Watson (1988), it is then possible to decompose the price vector into a permanent and transitory component. Gonzalo and Granger (1995) show an alternative decomposition of $p_{t}$ where the permanent component being a function of the values $p_{t}$. The vector of price $p_{t}$ is decomposed as follows:

$$
p_{t}=F_{1} f_{t}+F_{2} \tau_{t}
$$

where $f_{t}$ is the common long-memory component and $\tau_{t}$ is the stationary component. Two conditions are imposed: first, $f_{t}$ is an exact linear function of the current values of $p_{t}$, and second, the transitory component $\tau_{t}$ has no permanent effect on $p_{t}$. The assumptions make the identification of the common factor, and the observation of the common efficient price $f_{t}$ possible. The permanent component of the vector of prices $p_{t}$ in the Gonzalo Granger approach is defined a linear combination of the current values of the price vector, where linear combination is given by the structure of the A. Given the nature of the Gonzalo Granger decomposition and the following result:

$$
f_{t}=A^{\prime} p_{t}
$$

the $A$ matrix becomes a natural measure of the contribution to price discovery of market $i$. The higher the weight, the larger the contribution of the market to information. 


\section{Data}

The analysis is based on three different categories of data, namely intraday tic GLOBEX EUR/USD futures data, e-mini futures data from CME and net positions of different types of traders from CFTC which are reported weekly. The sample period is from January 2010 to December 2010, (252 trading days). Martinez and Tse (2019) find a significant improvement in the market quality for Mexican peso contracts when the Chicago Mercantile Exchange (CME) reduced the tic size.

\subsection{Futures Market Data}

Regular futures market data are EURO/USD futures traded on Chicago Mercantile Exchange (CME). More specifically, we use the best bid or offer (BBO) one-second intraday data. The EURO/USD futures contract traded on CME has a contract size of $€ 125,000$ with a minimum price fluctuation of $\$ 0.00005$ per euro increments ( $\$ 6.25 /$ contract). The electronic trading runs on the CME GLOBEX trading platform, from Sundays to Fridays, 17:00 CST to 16:00 CST (Central Standard Time). Trading closes at 16:00 CST on Fridays and opens on Sundays at 17:00 CST.

Trading on CME e-mini euro futures started in 1999 on CME GLOBEX. E-mini futures contracts are more affordable as their size is half compared to the size of the regular futures contracts. This is particularly convenient for traders with small margin accounts. The e-mini futures market dataset is the EURO/USD futures traded on Chicago Mercantile Exchange. The EURO/USD futures contract trade on CME, with contract size of $€ 62,500$ and a minimum price fluctuation of $\$ 0.0001$ per euro increments $(\$ 6.25 /$ contract). The trading time is the same as that of regular EUR/USD futures.

Data for CME include (filtered) 17,123,819 observations, while that for e-mini include $11,854,327$ observations. Following Hasbrouck (1995) approach to the trading price calculation, quotes are calculated as the average of bid-ask quoted prices. Table 1 reports summary statistics of log of average bid-ask price quotes of EUR/USD traded on CME for the regular and e-mini futures markets.

Table 1 reports summary statistics of log of average bid-ask price quotes of EUR/USD traded on CME for the regular and e-mini futures markets. Panel A of Table 1 reports summary statistics of one-second futures mid-quotes of EUR/USD traded on CME for Regular and e-mini futures markets. Panel B reports correlation coefficient between regular and e-mini futures data.

Table 1. Summary statistics.

\begin{tabular}{ccc}
\hline & Panel A & \\
\hline EUR/USD & Regular Futures & E-mini Futures \\
\hline Number of transactions & $17,123,819$ & $11,854,327$ \\
Mean & 0.282 & 0.253 \\
Standard deviation & 0.045 & 0.045 \\
Skewness & -0.285 & -0.065 \\
Kurtosis & -0.362 & 0.423 \\
Jarque-Bera & 6843.912 & 7988.588 \\
Average number of quotes per hour & 2945.26 & 2054.42 \\
\hline
\end{tabular}

Panel B

Correlation coefficient between

regular futures and e-mini futures Regular futures

$0.919^{* * *}$

Note: ${ }^{* * *}$ denotes statistically significant at $1 \%$.

The analysis of the distribution of the price series shows negative kurtosis for both the markets, indicating the presence of fat tails. The Jarque-Bera (J-B) test indicates that the midquote series in two markets are not normally distributed. There was significantly higher trading activity for regular futures, compared to the e-mini futures during the sample 
period. The total number of transactions is higher in regular futures than e-mini futures. Series are highly correlated (Pearson correlation). Regular futures have a substantially large number of quotes as compared to e-mini futures

\subsection{Futures Positioning Data}

The creation of CFTC dates back to 1974. Traders with positions above a certain level are required to report open interest on a weekly basis. This is to discourage and prevent collusion and market manipulation. Since 1992, on Friday each week, the positions data collected on Tuesday of the same week is released. ${ }^{11}$ The data include open interest, reportable positions, commercial and non-commercial traders, non-reportable positions, spreading, changes in commitments from previous reports, percent of open interest and number of traders.

Reportable positions identified by the CFTC are classified as either "commercial" (hedger) or "non-commercial" (speculator). All of the trader's reported futures positions in a commodity are classified as commercial if the trader uses futures contracts in that particular commodity for hedging. Mutual funds and corporate pension funds are examples of some of the types of companies that are classified as hedgers. Commodity trading advisors (CTA), as a group is an example of a non-commercial or a speculative trader in the futures market. CFTC also reports third category of position called "Non-reportable Positions". The long and short open interest shown as "Non-reportable Positions" is derived by subtracting total long and short "Reportable Positions" from the total open interest. Accordingly, for "Non-reportable Positions." the number of traders involved and the commercial/non-commercial classification of each trader are unknown. These data involve firms that are too small to classify hence are ignored for all practical purposes in this paper.

The CFTC classifies traders as commercial which include banks, hedge funds, mutual funds, corporate pension funds, currency dealers and nonfinancial corporations. ${ }^{12}$ The non-commercial trader forms the more homogenous group, which includes commoditytrading advisors who are profit driven. CFTC strictly monitors the activities of speculators, as they are keen to destabilize the market. Some traders classified as hedgers may act as speculators, but due to the monitoring by the CFTC, these traders have an incentive to be classified as commercial traders. To ensure that traders are classified with accuracy and consistency, CFTC staff may exercise judgment in re-classifying a trader if it has additional information about the trader's use of the markets.

The table represents summary statistics of CFTC positioning data. Panel A of Table 2 shows the raw average number of long and short contracts for each trader type for the regular futures contracts. The three columns of Panel B describe the ratio of open interest for trader type $i$ (commercial, noncommercial, non-reporter) relative to total open interest of all contracts.

Table 2. Summary statistics of Commodity Futures Trade Commission (CFTC) positioning data.

\begin{tabular}{|c|c|c|c|c|c|c|}
\hline \multicolumn{7}{|c|}{ Panel A } \\
\hline Index & \multicolumn{2}{|c|}{ Noncommercial } & \multicolumn{2}{|c|}{ Commercial } & \multicolumn{2}{|c|}{ Nonreportable } \\
\hline \multirow{2}{*}{$\begin{array}{l}\text { Regular } \\
\text { futures }\end{array}$} & Long & Short & Long & Short & Long & Short \\
\hline & 47,226 & 81,826 & 117,357 & 80,561 & 46,228 & 48,425 \\
\hline \multicolumn{7}{|c|}{ Panel B } \\
\hline \multicolumn{7}{|c|}{ Ratio of Trader Type Relative to Total Open Interest across Types } \\
\hline Index & \multicolumn{2}{|c|}{ Noncommercial } & \multicolumn{2}{|c|}{ Commercial } & \multicolumn{2}{|c|}{ Nonreportable } \\
\hline \multicolumn{7}{|l|}{ EUR/USD } \\
\hline $\begin{array}{l}\text { Regular } \\
\text { futures }\end{array}$ & \multicolumn{2}{|c|}{-0.0052} & \multicolumn{2}{|c|}{0.0036} & \multicolumn{2}{|c|}{-0.0004} \\
\hline
\end{tabular}


Panel A of Table 2 shows the raw average number of long and short contracts for each trader type for the regular futures contracts. Unfortunately, there is no availability of breakdown of trader type positions, for the e-mini futures contracts. Speculators normally take net short positions on average, while hedgers on an average take a net long position. ${ }^{13}$ Panel B of Table 2 shows the breakdown of trader type relative to total outstanding positions. To calculate the net position, we use the normalization method proposed by Schwarz (2011). The formula to calculate net position is:

$$
q_{t}^{i}=\frac{\operatorname{long}_{t}^{i}-\text { short }_{t}^{i}}{\sum \operatorname{long}_{t}^{j}+\sum \text { short }_{t}^{j}}
$$

where

long $g_{t}^{i}$ represents trader type $i$ with long and long positions at time $t$.

short $t_{t}^{i}$ represent tradertype $i$ with long and short positions at time $t$.

$J=1,2, \ldots, 52$ represents a weekly time stamp.

According to Schwarz (2011), this normalization will allow for the regression coefficients will have the same interpretation across all the different types of traders.

\section{Results}

Table 3 represents information share for the sample period from January to December 2010 .

Panel A describes one second sampling mean, median and standard deviation estimates relating to the information share (IS) of the regular and e-mini futures EUR/USD contract Panel B shows weekly sampling mean median and standard deviation estimates for 52 weeks. Information shares are computed from the vector error correction model (VECM) suggested by Hasbrouck (1995).

Table 3. Information shares (IS).

\begin{tabular}{|c|c|c|c|c|c|c|}
\hline \multicolumn{7}{|c|}{ Panel A } \\
\hline & \multicolumn{3}{|c|}{ Regular Contracts } & \multicolumn{3}{|c|}{ E-Mini Contracts } \\
\hline & $\begin{array}{l}\text { Lower } \\
\text { Bound }\end{array}$ & Midpoint & $\begin{array}{l}\text { Upper } \\
\text { Bound }\end{array}$ & $\begin{array}{l}\text { Lower } \\
\text { Bound }\end{array}$ & Midpoint & $\begin{array}{l}\text { Upper } \\
\text { Bound }\end{array}$ \\
\hline Mean & 0.394 & 0.665 & 0.935 & 0.188 & 0.334 & 0.479 \\
\hline Median & 0.463 & 0.728 & 0.993 & 0.264 & 0.414 & 0.563 \\
\hline SD & 0.063 & 0.208 & 0.353 & 0.072 & 0.192 & 0.311 \\
\hline \multicolumn{7}{|c|}{ Panel B } \\
\hline & \multicolumn{3}{|c|}{ Regular Contracts } & \multicolumn{3}{|c|}{ E-Mini Contracts } \\
\hline & $\begin{array}{l}\text { Lower } \\
\text { Bound }\end{array}$ & Midpoint & $\begin{array}{l}\text { Upper } \\
\text { Bound }\end{array}$ & $\begin{array}{l}\text { Lower } \\
\text { Bound }\end{array}$ & Midpoint & $\begin{array}{l}\text { Upper } \\
\text { Bound }\end{array}$ \\
\hline Mean & 0.345 & 0.619 & 0.892 & 0.172 & 0.328 & 0.484 \\
\hline Median & 0.459 & 0.707 & 0.954 & 0.248 & 0.376 & 0.504 \\
\hline SD & 0.052 & 0.201 & 0.349 & 0.065 & 0.185 & 0.304 \\
\hline
\end{tabular}

Following the standard practice, Panel A of Table 3 describes one-second sampling mean, median and standard deviation estimates relating to the information share (IS) of the regular and e-mini futures EUR/USD contracts. Since the lower and upper bounds do not provide a single measure of IS, Baillie et al. (2002), Booth et al. (2002) and many others propose that the mean of the upper and lower bounds is a reasonable estimate of a market's information share.

Panel A of Table 3 shows that regular futures contribute for $66.5 \%$ to price discovery whereas e-mini futures account for $33.4 \%$ of the price. Panel B shows weekly sampling mean median and standard deviation estimates. In this case regular futures contribute to the price discovery by $61.9 \%$ whereas e-mini futures contribute $32.8 \%$ to price discovery. 
Hence it can be stated that regular futures reflect information more efficiently compared to e-mini futures for both the intraday interval and the weekly interval.

This is consistent with a large body of literature indicating that the regular futures markets have several advantages like fewer constraints, lower transaction costs, and the ease of speculating and hedging guaranteed by the traded instruments, making it an ideal market for informed investors. These large investors are more likely to be institutional investors with greater financial, technical and analytical skills. These findings are evident given the lower trading activity in the e-mini futures market (Table 1) which is consistent with the notion that a liquid market is also more informative. Moreover, according to Cabrera et al. (2009), trading in the e-mini futures markets is concentrated among a few bankers and hence there might not be any informed traders in this market.

Table 4 show the effects of trader's positions on information share (IS) where information share of the regular futures is the dependent variable calculated using the weekly sampling interval on every Tuesday and is measured by the Hasbrouck (1995) approach.

Independent variables are non-commercial, commercial trader and non-reportable type position. $\ln ($.) denotes logarithm. The numbers in parentheses are $p$-values. The standard errors of the estimates are computed based on the procedure of Newey and West (1987) to adjust for the presence of heteroskedasticity and autocorrelation in the regression errors. The symbols ${ }^{* * *}, * *$ and ${ }^{*}$ denote significance at $1 \%, 5 \%$ and $10 \%$ level, respectively.

Table 4. Effects of trader's positions on information share.

\begin{tabular}{|c|c|c|c|c|}
\hline \multicolumn{5}{|c|}{ Dependent Variable: The Relative Contribution to Price Discovery } \\
\hline & [1] & [2] & [3] & [4] \\
\hline & Coefficient & Coefficient & Coefficient & Coefficient \\
\hline Constant & $\begin{array}{c}4.736^{* * *} \\
(0.000)\end{array}$ & $\begin{array}{c}3.763^{* * *} \\
(0.000)\end{array}$ & $\begin{array}{c}3.635^{* * *} \\
(0.000)\end{array}$ & $\begin{array}{c}3.987^{* * *} \\
(0.000)\end{array}$ \\
\hline Non-com & $\begin{array}{l}3.874 * * \\
(0.010)\end{array}$ & - & $\begin{array}{l}2.764^{* *} \\
(0.014)\end{array}$ & $\begin{array}{l}2.976 \text { ** } \\
(0.020)\end{array}$ \\
\hline Com & $\begin{array}{l}0.765 * \\
(0.096)\end{array}$ & $\begin{array}{c}1.763 \\
(0.852)\end{array}$ & - & $\begin{array}{c}0.635 \\
(0.071) *\end{array}$ \\
\hline Non-rep & $\begin{array}{c}1.763 \\
(0.873)\end{array}$ & $\begin{array}{l}-2.763 \\
(0.765)\end{array}$ & $\begin{array}{c}1.736 \\
(0.693)\end{array}$ & - \\
\hline Adjusted $R^{2}$ & 0.386 & 0.127 & 0.189 & 0.302 \\
\hline Nos & 52 & 52 & 52 & 52 \\
\hline
\end{tabular}

Table 4 reports the regression results of IS on the three trader types: speculators, hedgers and non-reportable traders (small traders). The unrestricted model [1] includes all the three trader types as explanatory variables while the restricted models $[2,3$ and 4] include two of the three trader type variables. In model [1], the logarithm of noncommercial traders is statistically significant at $5 \%$ level of significance and logarithm of commercial trader type is significant at $10 \%$ level of significant. The coefficient of non-reportable traders is not significant indicating that small traders have small and insignificant impact on the regular futures information share. The slope coefficient of non-commercial traders is higher than that of the commercial traders indicating that the IS of regular futures can be better explained by speculators than hedgers can; specifically, a $1 \%$ increase in the trader type position of the non-commercial traders leads to an increase in the IS by $3.874 \%$. In the restricted models, the coefficient of non-commercial traders is positive and significant at $5 \%$ level of significance, whereas the coefficient of commercial traders is positive but insignificant. Overall, the results suggest that speculator's trades have on average more information content.

Table 5 represents robustness check of information share for the sample period from January 2010 to December 2010. 
Panel A describes one second sampling mean, median and standard deviation estimates relating to the information share (IS) of the regular and e-mini futures EUR/USD contract Panel B shows weekly sampling mean median and standard deviation estimates for 52 weeks. Information shares are computed from the vector error correction model (VECM) suggested by Gonzalo and Granger (1995).

Table 5. Robustness check of information share: Gonzalo-Granger weights.

\begin{tabular}{|c|c|c|c|c|c|c|}
\hline \multicolumn{7}{|c|}{ Panel A } \\
\hline & \multicolumn{3}{|c|}{ Regular Contract Price } & \multicolumn{3}{|c|}{ E-Mini Contract Price } \\
\hline & $\begin{array}{l}\text { Lower } \\
\text { Bound }\end{array}$ & Midpoint & $\begin{array}{l}\text { Upper } \\
\text { Bound }\end{array}$ & $\begin{array}{l}\text { Lower } \\
\text { Bound }\end{array}$ & Midpoint & $\begin{array}{l}\text { Upper } \\
\text { Bound }\end{array}$ \\
\hline Mean & 0.298 & 0.597 & 0.896 & 0.125 & 0.312 & 0.498 \\
\hline Median & 0.421 & 0.682 & 0.942 & 0.243 & 0.393 & 0.543 \\
\hline SD & 0.201 & 0.279 & 0.356 & 0.134 & 0.194 & 0.253 \\
\hline \multicolumn{7}{|c|}{ Panel B } \\
\hline & \multicolumn{3}{|c|}{ Regular Contract Price } & \multicolumn{3}{|c|}{ E-Mini Contract Price } \\
\hline & $\begin{array}{l}\text { Lower } \\
\text { Bound }\end{array}$ & Midpoint & & $\begin{array}{l}\text { Lower } \\
\text { Bound }\end{array}$ & Midpoint & \\
\hline Mean & 0.374 & 0.634 & 0.893 & 0.163 & 0.343 & 0.523 \\
\hline Median & 0.465 & 0.711 & 0.956 & 0.294 & 0.402 & 0.509 \\
\hline SD & 0.198 & 0.266 & 0.334 & 0.129 & 0.171 & 0.213 \\
\hline
\end{tabular}

Table 5 shows the estimated price discovery contributions of the two markets; regular and e-mini EUR/USD futures markets for both one second and weekly sampling intervals. In Panel A, the common factor weights for one second interval, estimated jointly over all days by the Gonzalo and Granger (1995) model is $59.7 \%$ for regular futures and $31.2 \%$ for e-mini futures. Panel B presents weekly sampling interval and show that common factor weights for regular futures and e-mini futures is $63.4 \%$ and $34.3 \%$, respectively. This is similar to our initial findings that the regular futures may better capture the IS as compared to e-mini futures.

Table 6 represents robustness check for the effects of trader's positions on information share (IS) where information share of the regular futures is the dependent variable calculated using the weekly sampling interval on every Tuesday and is measured by the Gonzalo and Granger (1995) approach.

Independent variables are non-commercial, commercial and non-reportable trader type position. Ln denotes logarithm. The numbers in parentheses are p-values. The standard errors of the estimates are computed based on the procedure of Newey and West (1987) to adjust for the presence of heteroskedasticity and autocorrelation in the regression errors. The symbols ${ }^{* * *},{ }^{* *}$ and ${ }^{*}$ denote significance at $1 \%, 5 \%$ and $10 \%$ level, respectively.

Table 6 reports the regression results of IS calculated using the Gonzalo and Granger ( 1995) method on the three trader types; speculators, hedgers and non-reportable traders (small traders). Here we find that the coefficient of non-commercial traders is positive and significant at $5 \%$ level of significance, indicating that a $1 \%$ increase in the non-commercial trader type position will lead to a $2.84 \%$ increase in IS value of the regular futures contracts. The coefficient of commercial traders is also positive but not significant collaborating with the finding that that the IS of regular futures can be better explained by speculators than hedgers can. 
Table 6. Robustness check: effects of traders' positions on information share.

\begin{tabular}{ccccc}
\hline \multicolumn{5}{c}{ Dependent Variable: The Relative Contribution to Price Discovery } \\
\hline & {$[1]$} & {$[2]$} & {$[3]$} & {$[4]$} \\
\hline & Coefficient & Coefficient & Coefficient & Coefficient \\
\hline \multirow{2}{*}{ Constant } & $3.635^{* * *}$ & $4.722^{* * *}$ & $3.635^{* * *}$ & 3.983 \\
& $(0.000)$ & $(0.000)$ & $(0.000)$ & $(0.000)$ \\
\hline \multirow{2}{*}{ Non-com } & $2.836^{* *}$ & & $1.764^{* *}$ & $2.424^{* *}$ \\
& $(0.012)$ & - & $(0.027)$ & $(0.047)$ \\
\hline \multirow{2}{*}{ Com } & $0.236^{*}$ & -2.873 & & $1.042^{*}$ \\
& $(0.085)$ & $(0.927)$ & & $(0.057)$ \\
\hline \multirow{2}{*}{ Non-rep } & 2.732 & -2.763 & 2.872 & - \\
\hline Adjusted $R^{2}$ & $(0.873)$ & $(0.765)$ & $(0.524)$ & 0.293 \\
\hline Nos & 0.406 & 0.103 & 0.195 & 52 \\
\hline Note: ${ }^{* * *},{ }^{* *}$ and ${ }^{*}$ mean $1 \%, 5 \%$ and $10 \%$ significance. & 52 & 52 & \\
\hline
\end{tabular}

\section{Conclusions}

This study focuses on the investigation of the relative contribution by regular futures market and e-mini futures market to price discovery in EURO/USD futures market. The dataset includes high frequency data relative to the year 2010. The estimation of the relative contribution of each market is done using the information share approach of Hasbrouck (1995), Gonzalo and Granger (1995). Results show evidence of the dominant role of regular futures market in the price discovery process visa vie e-mini futures market. On average, regular futures contributes $66.5 \%$ to price discovery in the EURO/USD futures market. This proves our first hypothesis that that as compared to the e-mini futures market, the regular futures market contributes significantly to the price discovery in the EUR/USD market.

This study also analyzes the relationship between positioning of different types of participants (hedgers and speculators) and IS. Both restricted and unrestricted regressions are considered. We find a positive significant relationship between IS and both the speculative trade position and hedgers trade position. The slope coefficient of non-commercial trader type is higher relative to the commercial trader type indicating that the IS of regular futures can be better explained by speculators. This proves our second hypothesis that the IS of regular futures can be better explained by speculators than hedgers. This is consistent with Webb and Smith (1994), Wang et al. (1994) and Ates and Wang (2005) conclusion that liquidity is one of the components that determine the rate of price discovery in the foreign exchange futures markets. Future studies can be conducted for different time periods or for different currency markets and exchanges.

Author Contributions: Conceptualization, J.M.; methodology, J.M.; software, J.M.; validation, J.M. and A.C.; formal analysis, J.M.; investigation, J.M. and A.C.; resources, J.M.; data curation, J.M. and A.C.; writing-original draft preparation, J.M.; writing-review and editing, J.M. and A.C.; visualization, J.M. and A.C.; supervision, J.M.; project administration, J.M.; funding acquisition, J.M. All authors have read and agreed to the published version of the manuscript.

Funding: This research received no external funding.

Data Availability Statement: Not applicable.

Conflicts of Interest: The authors declare no conflict of interest.

\section{Notes}

1 E-mini trading is associated with higher transaction costs for larger trades. Brokerage commissions are charged on a per contract basis. Hence even if the bid-ask spread is smaller; the total transaction costs per dollar of trading volume will be higher in the E-mini market. Therefore, the logical conclusion is that E-mini market will be dominated by small investors and the institutional traders will trade in the lower cost regular futures markets. (Kurov and Lasser 2004). 
2 The data source is “Triennial Central Bank Survey-Report on Global Foreign Exchange Market Activity in 2010" for December 2010 from www.bis.org (accessed on 12 March 2012).

3 The data source is "Triennial Central Bank Survey-Report on Global Foreign Exchange Market Activity in 2010" for December 2010 from www.bis.org (accessed on 15 March 2012).

4 Data source is "Annual volume survey-2010" from Futures Industries Association (FIA) web site http:/ / www.futuresindustry. org/downloads/Volume-Mar_FI\%28R\%29.pdf (accessed on 2 March 2012).

5 Data source is from "Semi-Annual Foreign Exchange Volume Survey" from the Foreign Exchange Committee (FXC) website http:/ / www.newyorkfed.org/fxc/news/ (accessed on 3 March 2012) and CME monthly volume reports.

6 When an individual reportable trader is identified to the Commission, the trader is classified either as "commercial" or "noncommercial." All of a trader's reported futures positions in a commodity are classified as commercial if the trader uses futures contracts in that particular commodity for hedging as defined in CFTC Regulation 1.3(z), 17 CFR 1.3(z).

7 Noise traders enhance the market liquidity, but make the information discovery process longer. Kyle (1985), Feench and Roll (1986) present evidence that suggests the influence of noise trading is non-trivial.

8 Crain and Lee (1995) Martens and Kofman (1998) examine the price leadership between Regular futures and FX spot market for Deutschemark (DM)/USD exchange rate. Rosemberg and Traub (2007) compared currency futures markets from CME for Deutsche Mark, British Pound, Japanese Yen and Swiss Franc. Chatrath and Song (1998) investigate the intraday reactions in the yen futures market and spot market.

9 Poskitt (2009) compared GLOBEX and Reuters D3000 in the electronic sterling/dollar exchange while Chen and Gau (2010) compared CME and EBS for the EUR/USD and JPY/USD exchange rates.

10 Hasbrouck's approach (1995) has been widely used to access information share: Mizrach and Neely (2008), Forte and Peña (2009), Poskitt (2009), Cabrera et al. (2009), Chen and Gau (2010), and Frijns et al. (2010).

11 The positions data was collected semi-monthly and monthly before the year 1992.

12 A trader may be classified as a commercial trader in some commodities and as a non-commercial trader in other commodities. A single trading entity cannot be classified as both a commercial and non-commercial trader in the same commodity. Nonetheless, a multi-functional organization that has more than one trading entity may have each trading entity classified separately in a commodity. For example, a financial organization trading in financial futures may have a banking entity whose positions are classified as commercial and have a separate money-management entity whose positions are classified as non-commercial.

13 Hedgers are long 45 weeks out of 52 weeks in 2010, suggesting that they have a tendency to be buyers.

\section{References}

Ates, Aysegul, and George H. Wang. 2005. Information Transmission in Electronic Versus Open-Out-Cry Trading Systems: An Analysis of U.S. Equity Index Futures Markets. Journal of Futures Markets 25: 679-715. [CrossRef]

Baillie, Richard T., G. Geoffrey Booth, Yiuman Tse, and Tatyana Zabotina. 2002. Price Discovery and Common Factor Models. Journal of Financial Markets 5: 309-21. [CrossRef]

Barber, Brad M., and Terrance Odean. 2000. Trading Is Hazardous to Your Wealth: The Common Stock Investment Performance of Individual Investors. Journal of Finance 55: 773-806. [CrossRef]

Booth, G. Geoffrey, Ji-Chai Lin, Teppo Martikainen, and Yiuman Tse. 2002. Trading and Pricing in Upstairs and Downstairs Stock Markets. Review of Financial Studies 15: 1111-135. [CrossRef]

Cabrera, Juan, Tao Wang, and Jian Yang. 2009. Do Futures Lead Price Discovery in Electronic Foreign Exchange Markets? Journal of Futures Markets 29: 137-56. [CrossRef]

Chakravarty, Sugato. 2001. Stealth Trading: “Which Traders' Trades Move Stock Prices? Journal of Financial Economics 61: $289-307$. [CrossRef]

Chatrath, Arjun, and Frank Song. 1998. Information and Volatility in Futures and Spot Markets: The Case of the Japanese Yen. Journal of Futures Markets 18: 201-23. [CrossRef]

Chen, Yu-Lun, and Yin-Feng Gau. 2010. News Announcements and Price Discovery in Foreign Exchange Spot and Futures Markets. Journal of Banking and Finance 34: 1628-636. [CrossRef]

Chen, Yu-Lun, and Wei-Che Tsai. 2017. Determinants of price discovery in the VIX futures market. Journal of Empirical Finance 43: 59-73. [CrossRef]

Crain, Susan J., and Jae Ha Lee. 1995. Intraday Volatility in Interest Rate and Foreign Exchange Spot and Futures Markets. Journal of Futures Markets 15: 395-421.

Engle, Robert, and Granger W. J. Granger. 1987. Co-Integration and Error Correction: Representation, Estimation, and Testing. Econometrica 55: 251-76. [CrossRef]

Evans, Martin D. D., and Richard K. Lyons. 2002. Order Flow and Exchange Rate Dynamics. Journal of Political Economy 110: 170-80. [CrossRef]

Fassas, Athanasios P., and Costas Siriopoulos. 2019. Intraday Price Discovery and Volatility Spillovers in an Emerging Market. International Review of Economics and Finance 59: 333-46. [CrossRef]

Feench, Kenneth R., and Richard Roll. 1986. Stock Return Variances: The Arrival of Information and the Reaction of Traders. Journal of Financial Economics 17: 5-26. [CrossRef] 
Forte, Santiago, and Juan I. Peña. 2009. Credit Spreads: An Empirical Analysis On the Information Content of Stocks, Bonds, and Cds. Journal of Banking and Finance 33: 2013-25. [CrossRef]

Frijns, Bart, Aaron Gilbert, and Alireza Tourani-Rad. 2010. The Dynamics of Price Discovery for Cross-Listed Shares: Evidence From Australia and New Zealand. Journal of Banking and Finance 34: 498-508. [CrossRef]

Gonzalo, Jesus, and Clive Granger. 1995. Estimation of Common Long-Memory Components in Cointegrated Systems. Journal of Business and Economic Statistics 13: 27-36.

Gorton, Gary B., Fumio Hayashi, and K. Geert Rouwehnorst. 2012. The Fundamentals of Commodity Futures Returns. Review of Finance 17: 35-105. [CrossRef]

Greppmair, Stefan, and Erik Theissen. 2019. Small Is Beautiful? How the Introduction of Mini Futures Contracts Affects the Regular Contract. Cfr Working Paper No. 19-06. Available online: https:/ /www.econstor.eu/handle/10419/209651 (accessed on 1 March 2021).

Hasbrouck, Joel. 1995. One Security, Many Markets: Determining the Contributions to Price Discovery. Journal of Finance 50: 1175-99. [CrossRef]

Hasbrouck, Joel. 2003. Intraday Price Formation in U.S. Equity Index Markets. Journal of Finance 58: 2375-400. [CrossRef]

Hasbrouck, Joel. 2004. Liquidity in the Futures Pits: Inferring Market Dynamics From Incomplete Data. Journal of Financial and Quantitative Analysis 39: 305-26. [CrossRef]

Hoffmann, Arvid O. I., and Hersh Shefrin. 2014. Technical Analysis and Individual Investors. Journal of Economic Behavior E Organization 107: 487-511.

Inani, Sarveshwar Kumar. 2017. Price Discovery in Indian Stock Index Futures Market: New Evidence Based On Intraday Data. International Journal of Indian Culture and Business Management 14: 23. [CrossRef]

Johansen, Søren. 1988. Statistical Analysis of Cointegration Vectors. Journal of Economic Dynamics and Control 12: 231-54. [CrossRef]

Johansen, Søren. 1991. Estimation and Hypothesis Testing of Cointegration Vectors in Gaussian Vector Autoregressive Models. Econometrica 59: 1551-580. [CrossRef]

Klitgaard, Thomas, and Laura Weir. 2004. Exchange Rate Changes and Net Positions of Speculators in the Futures Market. Federal Reserve Bank of New York Economic Policy Review 10: 17-28.

Kurov, Alexander, and Dennis Lasser. 2004. Price Dynamics in the Regular and E-Mini Futures Markets. Journal of Financial and Quantitative Analysis 39: 365-84. [CrossRef]

Kyle, Albert S. 1985. Continuous Auctions and Insider Trading. Econometrica 53: 1315-335. [CrossRef]

Lakonishok, Josef, and Edwin Maberly. 1990. The Weekend Effect: Trading Patterns of Individual and Institutional Investors. Journal of Finance 45: 231-43. [CrossRef]

Li, Wei-Xuan, Clara Chia-Sheng Chen, and James Nguyen. 2020. Which Market Dominates the Price Discovery in Currency Markets? the Case of Chicago Mercantile Exchange and the Intercontinental Exchange. Global Finance Journal, 100593. [CrossRef]

Lyons, Richard K. 1995. Tests of Microstructural Hypotheses in the Foreign Exchange Market. Journal of Financial Economics 39: 321-51. [CrossRef]

Malmendier, Ulrike, and Devin M. Shanthikumar. 2007. Are Small Investors Naive About Incentives? Journal of Financial Economics 85: 457-89. [CrossRef]

Martens, Martin, and Paul Kofman. 1998. The Inefficiency of Reuters Foreign Exchange Quotes. Journal of Banking and Finance 22: 347-66. [CrossRef]

Martinez, Valeria, and Yiuman Tse. 2018. Intraday Price Discovery Analysis in the Foreign Exchange Market of an Emerging Economy: Mexico. Research in International Business and Finance 45: 271-84.

Martinez, Valeria, and Yiuman Tse. 2019. The Impact of Tick-Size Reductions in Foreign Currency Futures Markets. Finance Research Letters 28: 32-38. [CrossRef]

Mizrach, Bruce, and Christopher Neely. 2008. Information Shares in the Us Treasury Market. Journal of Banking and Finance 32: 1221-233. [CrossRef]

Narayana, Paresh Kumar, Dinh Hoang Bach Phana, Kannan Thuraisamya, and Joakim Westerlundab. 2016. Price discovery and asset pricing. Pacific-Basin Finance Journal 40: 224-35. [CrossRef]

Newey, Whitney K., and Kenneth D. West. 1987. A Simple, Positive Semi-Definite, Heteroskedasticity and Autocorrelation Consistent Covariance Matrix. Econometrica 55: 703-8. [CrossRef]

Nofsinger, John R., and Richard W. Sias. 1999. Herding and Feedback Trading By Institutional Investors. Journal of Finance 54: $2263-295$. [CrossRef]

Payne, Richard. 2003. Informed Trade in Spot Foreign Exchange Markets: An Empirical Investigation. Journal of International Economics 61: 307-29. [CrossRef]

Poskitt, Russell. 2009. Price Discovery in Electronic Foreign Exchange Markets: The Sterling/Dollar Market. The Journal of Futures Markets 30: 590-606. [CrossRef]

Rosemberg, Joshua V., and Leah G. Traub. 2007. Price Discovery in the Foreign Currency Futures and Spot Market. The Journal of Derivatives 17: 7-25. [CrossRef]

Scholes, Myron S. 1972. The Market for Securities: Substitution Versus Price Pressure and the Effects of Information On Share Prices. The Journal of Business 45: 179-211. [CrossRef]

Schwarz, Gideon E. 1978. Estimating the Dimension of A Model. Annals of Statistics 6: 461-64. [CrossRef] 
Schwarz, Krista. 2011. Are Speculators Informed? The Journal of Futures Markets 32: 1-23. [CrossRef]

Stock, James H., and Mark W. Watson. 1988. Variable Trends in Economic Time Series. Journal of Economic Perspectives 2: 147-74. [CrossRef]

Subrahmanyam, Avanidhar. 1991. A Theory of Trading Stock Index Futures. Review of Financial Studies 4: 17-51. [CrossRef]

Tao, Libin, and Frank M. Song. 2010. Do Small Traders Contribute to Price Discovery? Evidence From Hong Kong Hang Seng Index Market. The Journal of Futures Market 30: 156-74. [CrossRef]

Theissen, Erik. 2002. Price Discovery in Floor and Screen Trading Systems. Journal of Empirical Finance 9: 455-74. [CrossRef]

Tse, Yiuman, and Ju Xiang. 2005. Market Quality and Price Discovery: Introduction of the E-Mini Energy Futures. Global Finance Journal 16: 164-79. [CrossRef]

Tse, Yiuman, Ju Xiang, and Joseph K. W. Fung. 2006. Price Discovery in the Foreign Exchange Futures Market. Journal of Futures Markets 26: 1131-143. [CrossRef]

Wang, George, Raphael Michalski, James Jordan, and Eugene Moriarty. 1994. An Intraday Analysis of Bid-Ask Spreads and Price Volatility in the S\&P 500 Index Futures Markets. Journal of Futures Markets 14: 837-59.

Webb, Robert I., and David G. Smith. 1994. The Effect of Market Opening and Closing On Volatility of Eurodollar Futures Prices. Journal of Futures Markets 14: 51-78. [CrossRef]

Yao, Jian. 1998. Market Making in the Interbank Foreign Exchange Market. Working Paper S-98-3. New York, NY, USA: New York University Salomon Center. 